\section{Internal Grants}

\section{QUST-2-CENG-2020-16}

PI Name:

Dr. Mark David Major, AICP, CNU-A
Students:

Raghad Alatoom 201601688

Ghalya Al-Maadeed 201802490

Aljazi Al-Banai

Hanae Taha

201801604

201610104

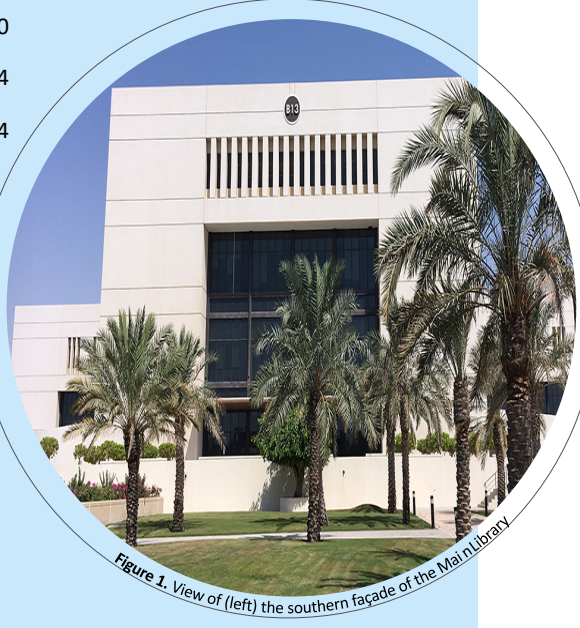

The Research and its Purpose

- Conducted a post-occupancy evaluation of the QU Main Library, drawing

on fieldwork observations of entries, movement, and room/space use.

- This will positively contribute to future design refinements, alterations, and new university buildings in creating a world-class center of education and research.

\section{How can we study its success?}

- Collect information to determine the use of each space in the building

- Direct observations of the use of the library and the space

functions

QU library

Abstract

- It is the most important building on campus.

- Serves many needs: educational and professional.

- Opened in 2012.

- Located at the center of the university, therefore referred

to as 'Heart of the university'.

- Building plot of $\sim 26,725$ square meters (m2) about 400

meters (m).

- Given its importance on campus, it's been used as an

environment behavior study and space syntax research.

- Main purpose of study : is the building used as intended in

its design?

\section{Methodology}

The study involved two rounds
Round 1

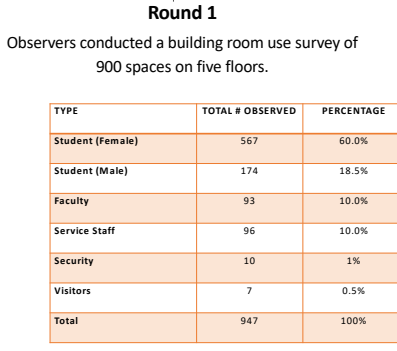

Demographics of building users of the QU Main Library based on entire weekday from 7:00 am to 5:00 pm

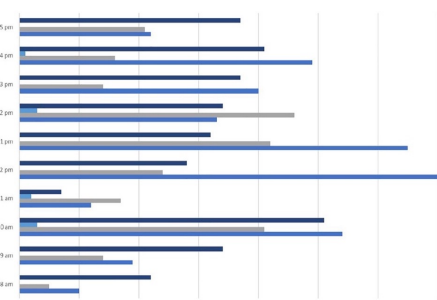

Total observed use of the Qu Main Library acess points over time from 7:00 am until 5:00 pm during a typical weekday

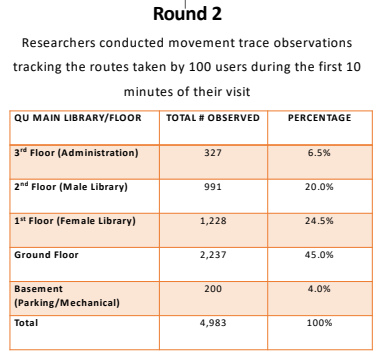

Total number and percentage use of each floor of the QU Main Library based on the static snapshots of all public spaces of the building over an entire weekday from 7:00 am to 5:00 pm

\section{Discussion}

The purpose of this study is to observe the movement and space use, and space syntax modeling to further demonstrate that the QU Main Library is well-designed for its purpose. As the study shows the building is successfully used as what it was intended for, although some areas were not designed efficiently like the male vertical access to the library, other design strategies would have been more cost effective. The architects' use of a 'traditional' cross-axis arrangement for the layout highlights the efficiency of this method in this type of building, because of this layout circulation and accessibility throughout

\section{Results}

Entry and Exit Counts at Library Access Points

\begin{tabular}{|l|c|c|c|}
\hline QU MAIN LIBRARY ACCESS POINTS & $\begin{array}{c}\text { ENTRY } \\
\text { (People/hour) }\end{array}$ & $\begin{array}{c}\text { Exit } \\
\text { (People/hour) }\end{array}$ & TOTAL (People/hour) \\
\hline Main (North) Entrance & 271.5 & 291.0 & 562.5 \\
\hline Male (East) Entrance & 285.0 & 199.5 & 484.5 \\
\hline Female (West) Entrance & 186.0 & 174.0 & 360.0 \\
\hline Restricted (South) Entrance & 6.0 & 7.5 & 13.5 \\
\hline Total & 748.5 & 672.0 & $1,420.5$ \\
\hline
\end{tabular}

Average number people per hour entering and exiting the four ground level access points of the QU

\section{Movement Patterns}

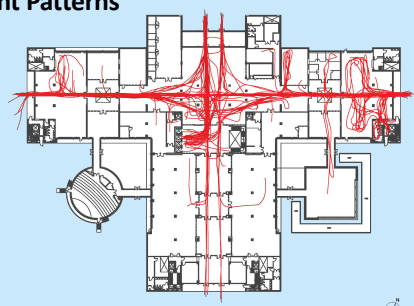

Sitting, Standing, and Interacting in the Library

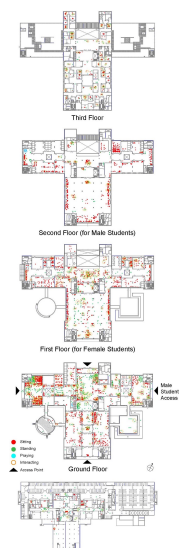

Space Syntax Modeling

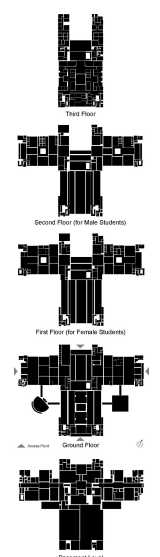

Figure 3. Convex mapping
(Source: QUST-2-CENG-2020-16)
Imeracting, and praying on all flitiors of of the QU Main Library during a typical we
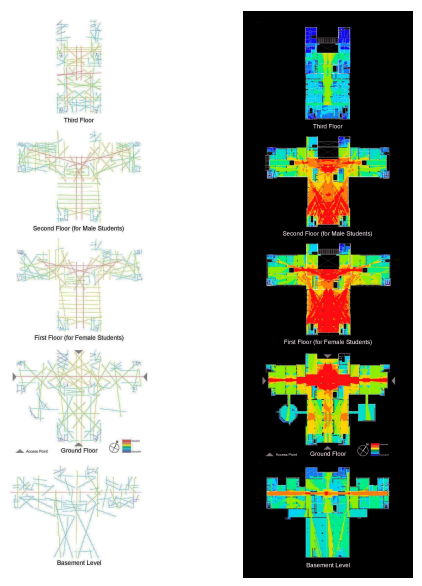

Figure 4. Axial analysis of
individual floors. (Isource:

Figure 5. Pattern of integration (radiuss) in
the visibility graph analysis (VGA) of individual
floors of the 